\title{
CARACTERIZACIÓN DEL USUARIO DE E-COMMERCE EN EL ÁREA METROPOLITANA CENTRO OCCIDENTE DE PEREIRA
}

Isabella Monsalve Montoya*

\section{Resumen}

El mercado como el consumidor durante los últimos años han experimentado una gran evolución, todo gracias a la aparición de los medios de comunicación, entre ellos el internet es una de las herramientas más utilizadas por el usuario. Por esta razón, se han modificado también las opciones de compra disponibles para los consumidores, cambiando así sus hábitos, comportamientos y expectativas frente a este nuevo proceso de compra. Por tanto, en la presente investigación se identificarán las principales características y variables que influyen en el comportamiento de compra del usuario e-commerce, en el área metropolitana centro occidente de Pereira, para así poder determinar el perfil de este usuario.

Con esta investigación se espera ayudar a las empresas, a la industria y al mercado en general a encontrar y diseñar estrategias y experiencias de compra, según la característica representativa del usuario e-commerce.

Palabras clave: características, comercio electrónico, comportamiento, consumidor, mercadeo.

* Estudiante, Administración de Negocios Internacionales. Fundación Universitaria del Área Andina. Correo: imonsalve6@estudiantes.areandina.edu.co 


\section{Introducción}

En esta investigación se hablará acerca de la caracterización del usuario de e-commerce en el área metropolitana centro occidente de Pereira. Para empezar, el e-commerce empieza y nace en 1960 con la creación del EDI (intercambio de datos electrónicos), o por sus siglas en inglés (electrónic data interchange), el cual permitió a las empresas el intercambio de información personal y las transacciones electrónicas. En 1970, aparecen las primeras computadoras; sin embargo, estas ofrecían un servicio muy limitado. En 1980, se moderniza el mercado y las ventas por catálogo gracias a los televisores o "televentas". En 1989, nacen las WWW (World Wide Web), este fue el gran momento decisivo para las tecnologías y la innovación más importante. A finales de los años noventa e inicios del 2000 el comercio electrónico creció y nacieron las compañías dedicadas únicamente al mercado online (Lynkoo, 2012).

Desde entonces, el mundo digital, las redes sociales, los teléfonos celulares, tabletas, computadoras, entre otros, entraron en furor y se convirtieron en nuestro día a día y nuestra principal fuente de información. Hoy, el usuario y el consumidor de e-commerce tienen todo a su alcance y tras de esto se han desarrollado características importantes en cada uno de ellos, desde sus gustos, hábitos, maneras de comprar, preferencias, entre otros aspectos.

Teniendo claro lo anterior, la investigación busca encontrar características importantes en los usuarios de e-commerce en el área metropolitana centro occidente de Pereira. Del mismo modo, se habló acerca de los problemas, los resultados de las diferentes variables presentadas para conocer el perfil del consumidor; en estas, se encuentran reflejadas las respuestas de los encuestados con los respectivos análisis. Adicional a lo anterior, se hizo un perfil general y un perfil para mujeres y hombres, los cuales son descritos con base en los resultados obtenidos. Por último, se encuentran las conclusiones y la opinión sobre el usuario del área metropolitana.

El diseño de la investigación se realizó con carácter cuantitativo, puesto que es más útil para la tabulación de la información y su organización en gráficas estadísticas. Asimismo, algunas definiciones de las palabras más frecuentes y nombradas dentro del documento son las siguientes:

El consumidor, "es aquel que adquiere un producto o servicio para satisfacer sus necesidades a cambio de dinero" (Galán, 2020). Las características, "son cualidades o rasgos que definen e identifican a una persona por su edad, gustos, habilidades, preferencias, género, orientación sexual, entre otras" (Significados, 2019). El comercio electrónico o e-commerce, "es un intercambio de bienes y de servicios a través de la web o internet gracias a los aparatos electrónicos que nos permiten navegar y descubrir nuevos sitios" (Ramos, 2020). El comportamiento, "es la manera de interactuar, reaccionar $y$ funcionar de una persona ante una situación y medio en el que se encuentra" (Significados, 2018). Por último, el mercadeo "es una herramienta utilizada por 
las empresas para estudiar problemas, necesidades, gustos, tendencias, entre otros, de un público o población”.

\section{Metodología}

\section{Tipo de investigación}

La investigación será de carácter cuantitativo, ya que se va a recopilar información de carácter primario para armar y caracterizar el perfil del consumidor de e-commerce; todo esto, en cuanto a sus gustos, preferencias, tiendas de interés, plataformas, entre otros aspectos, que permitirán predecir el comportamiento del usuario en el área metropolitana centro occidente de Pereira. En cuanto al alcance, este llegará hasta el ámbito descriptivo, con el fin de determinar la conducta que tienen las personas a la hora de comprar por internet.

\section{Población y muestra}

La población en esta investigación son los usuarios entre las edades de 18 a 60 años, tanto hombres como mujeres que cuenten con acceso a internet. Con respecto a la muestra, se utilizó la página web del DANE para recolectar información; con ello, se determinó una población de 442073 personas en Pereira, Dosquebradas y La Virginia. Para la realización de la muestra se utilizó la fórmula de poblaciones finitas con un nivel de confianza del $95 \%$, error de estimación del $5 \%$ y un margen de éxito y de fracaso del $50 \%$, obteniendo un valor de 384 que será el número de encuestas que se harán en el área metropolitana centro occidente de Pereira. Para hacer la escogencia de las personas, se hará el muestreo no probabilístico de conveniencia, debido a su conveniente accesibilidad y proximidad a los usuarios.

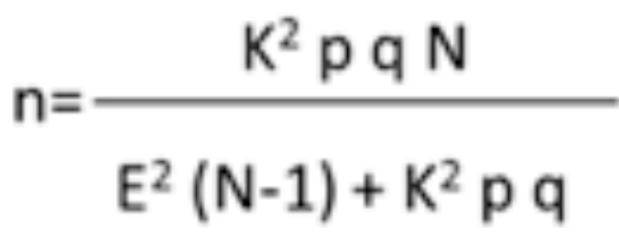

Nota. Adaptado de Tablas tamaño muestral, por Yanna Stefanu (2015), (http://www.estudiosmercado.com/ tablas-tamano-muestral/).

\section{Instrumento de recolección de información}

Se construyó un instrumento tipo encuesta teniendo en cuenta los objetivos planificados, esto permitirá la recolección primaria de la información para la caracterización de los usuarios en el área metropolitana centro occidente de Pereira.

\section{Resultados esperados}

Se espera que la investigación arroje información de las principales características de los usuarios del e-commerce, que permita a los empresarios establecer estrategias de ventas para así lograr incrementar sus ventas, puesto que este medio día a día se hará más atractivo para los consumidores y más para la nueva generación.

\section{Agradecimientos}

En la presente investigación se agradece al profesor y docente de la universidad del Areandina John Jairo Marín Restrepo, quien estuvo presente y a disposición de atender cualquier duda, revisión 


\section{Referencias}

1. Galán, J. S. (2020). Consumidor. https://economipedia.com/definiciones/consumidor.html

2. Giraldo, V. (2018). Guía completa de mercadeo: aprende el concepto y cómo crear una estrategia de crecimiento para tu marca. https://rockcontent.com/es/blog/ que-es-mercadeo/

3. Lynkoo. (2012). La historia del comercio electrónico. https://www.lynkoo.com/ la-historia-del-comercio-electronico/
4. Ramos, M. (2020). Qué es el eCommerce: definición modelos y ventajas. https://marketing4ecommerce. $\mathrm{mx} /$ que-es-el-ecommerce/

5. Significados. (2018). Significado de comportamiento. https://www.significados.com/comportamiento/

6. Significados. (2019). Significado de característica. https://www.significados.com/ caracteristica/ 